\title{
Qualidade fisiológica de sementes de amendoim forrageiro submetidas a diferentes tempos e ambientes de armazenamento
}

\author{
Physiological quality of peanut forage seeds submitted to different storage times and \\ environments
}

\author{
MEDEIROS, Lucilene Tavares ${ }^{1 *}$; SALES, Juliana de Fátima ${ }^{1}$; SOUZA,Rodolfo Gomes \\ $\mathrm{de}^{2}$; ALVES,Bruno Araújo ${ }^{2}$; FREITAS, Nulciene Firmino de ${ }^{2}$
}

\author{
${ }^{1}$ Instituto Federal Goiano, Programa de Pós-Graduação em Zootecnia, Departamento de Zootecnia, Rio \\ Verde, Goiás, Brasil. \\ ${ }^{2}$ Instituto Federal Goiano, Programa de Pós Graduação em Zootecnia e Ciências Agrárias, Rio Verde, \\ Goiás, Brasil \\ *Endereço para correspondência: tavaresmedeiros@yahoo.com.br
}

\section{RESUMO}

O sucesso no estabelecimento e produção de pastagens depende de uma boa qualidade da semente, sendo que a semente representa apenas cerca de $10 \%$ do custo total de formação da pastagem. Diante deste fato o objetivo do presente trabalho foi comparar diferentes tempos $(0 ; 4 ; 8$ e 12 meses $)$ de armazenamento em (B.O.D regulada a $\left.10^{\circ} \mathrm{C}\right) ;\left(\right.$ Geladeira $00^{\circ} \mathrm{C} \pm$ $5^{\circ} \mathrm{C}$ ) e Laboratório a $26^{\circ} \mathrm{C} \pm 3{ }^{\circ} \mathrm{C}$ não há necessidade de parênteses para separar os tratamentos em sementes de Arachis pintoi cv. Amarillo. As sementes utilizadas foram tratadas com fungicida Vitavax-Thiram ${ }^{\circledR}$ [Ingrediente Ativo (carboxina + tiram): $200+200 \mathrm{~g} / \mathrm{L}]$, na dosagem de $300 \mathrm{~mL}$ de fungicida diluídos em $500 \mathrm{~mL}$ de água para $100 \mathrm{~kg}$ de sementes. O delineamento experimental utilizado foi $\mathrm{em}$ blocos inteiramente casualizado (DBC), dispostos em um esquema fatorial $4 \times 3$ sendo quatro tempos de armazenamento $(0,4,8$ e 12 meses), três ambientes (Laboratório, Geladeira e incubadora B.O.D) com quatro repetições. Os resultados foram submetidos à análise de variância, regressão e as médias comparadas pelo teste de Tukey e F, a 5\% de probabilidade. As sementes armazenadas em baixas temperaturas, mesmo no maior tempo de armazenamento estudado, mantêm sua qualidade fisiológica, indicando que baixas temperaturas exercem efeito positivo na conservação das sementes.

Palavras-chave: Arachis pintoi, pastagens, sementes

\section{SUMMARY}

The successful establishment and production of pasture depends on a good seed quality, and the seed represents only about $10 \%$ of the total cost of the pasture formation. Considering this fact, the aim of the present study was to compare different times $(0 ; 4 ; 8$ and 12 months) of storage $\left(\mathrm{BOD}\right.$ set at $\left.10^{\circ} \mathrm{C}\right)$, (Refrigerator $00^{\circ} \mathrm{C} \pm$ $5^{\circ} \mathrm{C}$ ) and ( $\mathrm{Lab}$ at $26^{\circ} \mathrm{C} \pm 3^{\circ} \mathrm{C}$ ) in seeds of Arachis pintoi cv. Amarillo. The seeds used were treated with the fungicide Vitavax-Thiram ( ${ }^{2}$ [Active Ingredient (carboxin + thiram): $200+$ $200 \mathrm{~g} / \mathrm{L}]$ at a dosage of $300 \mathrm{ml}$ of fungicide diluted in $500 \mathrm{~mL}$ of water to $100 \mathrm{~kg}$ of seeds. The experimental design was in completely randomized blocks (DBC), arranged in a $4 \times 3$ factorial scheme with four storage times $(0 ; 4 ; 8$ and 12 months), three environments (Lab, Refrigerator and B.O.D.) with four repetitions. The results were submitted to analysis of variance, the regression and the means were compared by the Tukey test and F, at 5\% probability. The seeds stored at low temperatures, even in the highest storage time studied, maintain their physiological quality, indicating that low temperatures have a positive effect on seed conservation.

Keywords: Arachis pintoi, pastures, seeds 


\section{INTRODUÇÃO}

A utilização de leguminosas forrageiras do gênero Arachis L. em pastagens brasileiras, ainda é incipiente. Porém, o interesse é crescente e já consolidado em várias regiões do Brasil (VALENTIM et. Al., 2003).

A espécie é exclusiva da flora brasileira, sendo encontrada desde o Planalto Central, em Goiás, até o litoral da Bahia, nos biomas Mata Atlântica e Cerrado (BRASIL, 2012).

$\mathrm{O}$ amendoim forrageiro apresenta ampla faixa de adaptação, desenvolvendo-se bem desde o nível do mar até $1.800 \mathrm{~m}$ de altitude, em áreas com precipitação pluviométrica anual superior a $1.200 \mathrm{~mm}$ e temperaturas média de $22^{\circ} \mathrm{C}$ a $28^{\circ} \mathrm{C}$. Avaliações feitas no Sul do Brasil mostram que $o$ amendoim forrageiro possui boa tolerância a geadas, apresentando perda de folhas $\mathrm{e}$ paralisação do crescimento, porém com rebrotação vigorosa com o aumento da temperatura durante a primavera $(\mathrm{COX}$, 2012). Mesmo com suas importantes caraterísticas, ainda possui um número baixo de informações científicas, especialmente na área de produção e tecnologia de sementes (AMATO, et al., 2007).

O estabelecimento desta leguminosa é mais rápido quando o plantio é feito por sementes do que quando são utilizados estolões (VALENTIM et. al., 2003).

Esta forrageira apresenta um indeterminado período de florescimento e à característica de desenvolvimento subterrâneo dos frutos, geralmente com uma semente (CARVALHO \& NAKAGAWA, 2000).

O uso de sementes sem o conhecimento de sua qualidade pode conduzir ao risco de semear uma quantidade abaixo do ideal, conduzir a uma baixa densidade de plantas por área, o que possibilita a competição por plantas invasoras, além de, consequentemente contribuir para a degradação das pastagens.

O período de viabilidade das sementes de amendoim forrageiro, definido por fatores fisiológicos, inerentes à própria semente e fatores ambientais, físicos ou químicos ainda não estão bem definidos. Portanto, em virtude do grande potencial e a recente introdução do gênero Arachis nas pastagens brasileiras e ao baixo número de informações sobre o comportamento das sementes submetidas a diferentes ambientes e tempo de armazenamento, há a necessidade de realizar estudos mais detalhados, objetivando obter maior êxito na pecuária de corte e leite do Brasil.

Objetivou-se com este trabalho foi comparar diferentes tempos de armazenamento $(0 ; 4 ; 8$ e 12 meses $)$ em B.O.D regulada a $10^{\circ} \mathrm{C}$; Geladeira $00^{\circ} \mathrm{C}$ $\pm 5^{\circ} \mathrm{C}$ e Laboratório a $26^{\circ} \mathrm{C} \pm 3^{\circ} \mathrm{C}$ em sementes de Arachis pintoi cv. Amarillo.

\section{MATERIAL E MÉTODOS}

O experimento foi realizado no Laboratório de Sementes do Instituto Federal de Educação, Ciência e Tecnologia Goiano - Campus Rio Verde. As sementes foram adquiridas da Empresa Matsuda Sementes de São Sebastião do Paraíso - MG em janeiro de 2010.

$\mathrm{O}$ teor de umidade das sementes foi determinado segundo as Regras de Análise de Sementes (RAS), utilizando o método da estufa a $105 \pm 3^{\circ} \mathrm{C}$ durante 24h, (BRASIL, 2009) sendo esta umidade inicial de $12 \%$. As sementes foram armazenadas em ambiente de laboratório (LAB) a $26^{\circ} \mathrm{C} \pm 3^{\circ} \mathrm{C}$, na B.O.D regulada a $10^{\circ} \mathrm{C}$ e geladeira 
(GEL) a $00^{\circ} \mathrm{C} \pm 5^{\circ} \mathrm{C}$, por $0,4,8$ e 12 meses em embalagens plásticas à vácuo. As sementes utilizadas foram tratadas com fungicida Vitavax-Thiram ${ }^{\circledR}$ [Ingrediente Ativo (carboxina + tiram): $200+200 \mathrm{~g} / \mathrm{L}]$, na dosagem de $300 \mathrm{~mL}$ de fungicida diluídos em $500 \mathrm{ml}$ de água para $100 \mathrm{~kg}$ de sementes.

As sementes foram colocadas para germinar em germinador modelo "Marconi", regulado à temperatura de $30^{\circ} \mathrm{C}$, em substrato umedecido utilizando-se 2,5 vezes o peso do substrato seco. Foram utilizadas quatro repetições com 50 sementes cada. $\mathrm{O}$ teste de emergência foi realizado com plantio à $3 \mathrm{~cm}$ de profundidade em canteiros de areia em casa de vegetação com aproximadamente $23,48^{\circ} \mathrm{C}$ de temperatura média e $90,12 \%$ de umidade média, medidas pelo Registrador, modelo LogBox RHT LCD.

Foram realizadas contagens diárias, a fim de se determinar a porcentagem de germinação após completa estabilização e o IVG (Índice de Velocidade de Germinação), que foi calculado segundo Maguirre (1962).

O delineamento experimental utilizado foi em blocos inteiramente casualizados (DBC), dispostos $4 \times 3$, sendo quatro tempos de armazenamento $(0 ; 4 ; 8$ e 12 meses), três ambientes (laboratório a $26^{\circ} \mathrm{C} \pm 3^{\circ} \mathrm{C}$; incubadora B.O.D regulada a $10^{\circ} \mathrm{C}$ e geladeira a $00^{\circ} \mathrm{C} \pm 5^{\circ} \mathrm{C}$ ) com quatro repetições. Os resultados foram submetidos à análise de variância $(\mathrm{F}<0,05)$, regressão e as médias comparadas pelo teste de Tukey e F, a $5 \%$ de probabilidade.

\section{RESULTADOS E DISCUSSÃO}

Verificou-se diferença apenas nos dois maiores tempos de armazenamento (Tabela 1). O tempo de armazenamento promoveu diferenças no percentual de emergência, demonstrando uma tendência à remoção da dormência das sementes pelo tempo e, quando comparados os ambientes de armazenamento o maior percentual de germinação foi observado no ambiente B.O.D, seguido do ambiente geladeira da GEL (Tabela 1). Sabe-se que as sementes de amendoimforrageiro apresentam dormência primária até cerca de 6 a 8 meses após a colheita. Ambientes com as menores temperaturas promoveram melhor emergência quando comparadas à temperaturas mais elevadas, isto se deve ao fato que em temperaturas mais elevadas, as sementes respiram mais intensamente, degradando as reservas que lhe seriam necessárias no momento da germinação.

Tabela 1. Percentual de emergência (\% E) de sementes de Arachis pintoi cv. Amarillo em diferentes tempos e ambientes de armazenamento

\begin{tabular}{cccc}
\hline \multicolumn{4}{c}{ Ambientes de armazenamento } \\
\hline Armazenamento (meses) & Laboratório & $\begin{array}{c}\text { BOD } \\
\text { (incubadora) }\end{array}$ & Geladeira \\
\hline 0 & $46,75^{\mathrm{bcA}}$ & $48,25^{\mathrm{cA}}$ & $49,25^{\mathrm{cA}}$ \\
4 & $45,25^{\mathrm{cA}}$ & $46,25^{\mathrm{cA}}$ & $47,00^{\mathrm{cA}}$ \\
8 & $49,75^{\mathrm{bC}}$ & $57,00^{\mathrm{bA}}$ & $53,25^{\mathrm{bB}}$ \\
12 & $54,75^{\mathrm{aC}}$ & $67,50^{\mathrm{aA}}$ & $63,75^{\mathrm{aB}}$ \\
\hline
\end{tabular}

Laboratório $\left(26^{\circ} \mathrm{C} \pm 3^{\circ} \mathrm{C}\right)$; B.O.D.- incubadora $\left(10^{\circ} \mathrm{C}\right)$; Geladeira $\left(0^{\circ} \mathrm{C} \pm 5 \mathrm{C}\right)$. Médias seguidas de mesma letra minúscula nas colunas e de mesma letra maiúscula nas linhas não diferem entre si segundo o teste de Tukey $(\mathrm{P}<0,05)$. 
A germinação é um processo de grande importância no estabelecimento e perenidade de uma cultura, dessa forma observou-se que ambientes com temperaturas menores obtiveram os maiores percentuais de germinação nas sementes de Arachis pintoi cv. Amarillo (Tabela 2), este comportamento possivelmente possa ser atribuído ao fato de que, quando as sementes foram armazenadas em temperatura ambiente, houve deterioração das mesmas pela aceleração dos processos fisiológicos, como a respiração e ação de microrganismos patogênicos. Esta espécie, por ser de recente utilização, não apresenta ainda recomendações para a metodologia do teste de germinação nas Regras para Análise de Sementes - RAS (BRASIL, 2009). A temperatura ótima para a germinação varia de acordo com as espécies, sendo esta definida geneticamente e, também, em função das condições físiológicas das sementes (CARVALHO \& NAKAGAWA, 2000).

Tabela 2. Percentual de germinação (\% G) de sementes de Arachis pintoi cv. Amarillo em diferentes tempos e ambientes de armazenamento

\begin{tabular}{ll}
\hline \multicolumn{2}{l}{ Ambientes de armazenamento } \\
\hline Laboratório & $81,68^{\mathrm{b}}$ \\
BOD (incubadora) & $85,06^{\mathrm{a}}$ \\
Geladeira & $85,68^{\mathrm{a}}$ \\
\hline
\end{tabular}

Médias seguidas de letras distintas na coluna diferem entre si pelo teste Tukey $(\mathrm{P}<0,05)$.

Para a variável, índice de velocidade de emergência (IVE), observou interação significativa tempo $\mathrm{x}$ ambientes de armazenamento $(\mathrm{P}<0,05)$.

Verificou que os maiores índices de emergência ocorreram no ambiente B.O.D, seguido da geladeira (Tabela 3), e, os menores índices foram observados no ambiente de laboratório, fato que pode ser associado ao maior percentual de deterioração das sementes causado pelas temperaturas mais elevadas neste ambiente. Já, comparando a influência dos diferentes tempos, observa-se que de modo geral, os maiores índices de velocidade de emergência ocorreram aos 12 meses de armazenamento (Tabela 3), fato que pode relacionar à superação de dormência ocorrida neste período.

Tabela 3. Índice de velocidade de emergência (IVE) de sementes de Arachis pintoi cv. Amarillo em diferentes tempos e ambientes de armazenamento

\begin{tabular}{cccc}
\hline \multicolumn{4}{c}{ Ambientes de armazenamento } \\
\hline Armazenamento (meses) & Laboratório & BOD (incubadora) & Geladeira \\
\hline 0 & $15,54^{\mathrm{aA}}$ & $15,21^{\mathrm{cA}}$ & $15,22^{\mathrm{cA}}$ \\
4 & $15,14^{\mathrm{bA}}$ & $15,63^{\mathrm{cA}}$ & $15,60^{\mathrm{cA}}$ \\
8 & $16,05^{\mathrm{abC}}$ & $20,16^{\mathrm{bA}}$ & $18,85^{\mathrm{bB}}$ \\
12 & $16,55^{\mathrm{aC}}$ & $23,90^{\mathrm{aA}}$ & $22,01^{\mathrm{aB}}$ \\
\hline
\end{tabular}

Médias seguidas de mesma letra minúscula nas colunas e de mesma letra maiúscula nas linhas não diferem entre si segundo o teste de Tukey $(\mathrm{P}<0,05)$. 
Observa-se que os maiores índices foram observados no ambiente B.O.D e, quando comparados a mesma variável nos diferentes tempos, os maiores índices de velocidade de germinação foram observados aos 12 meses, seguido dos oito meses de armazenamento (Tabela
4). Este fato corrobora aos resultados observados na variável IVE (Tabela 3). Os maiores índices de germinação foram observados após quatro meses de armazenamento (COSTA \& ROSSETO, 2008).

Tabela 4. Índice de velocidade de germinação (IVG) em sementes de Arachis pintoi cv. Amarillo sob diferentes tempos e ambientes de armazenamento

\begin{tabular}{cccc}
\hline \multicolumn{4}{c}{ Ambientes de armazenamento } \\
\hline Armazenamento (meses) & Laboratório & BOD (incubadora) & Geladeira \\
\hline 0 & $32,32^{\mathrm{aA}}$ & $31,83^{\mathrm{cA}}$ & $31,27^{\mathrm{abA}}$ \\
4 & $31,77^{\mathrm{aA}}$ & $32,73^{\mathrm{cA}}$ & $32,49^{\mathrm{aA}}$ \\
8 & $32,81^{\mathrm{aB}}$ & $36,12^{\mathrm{bA}}$ & $30,55^{\mathrm{abC}}$ \\
12 & $33,31^{\mathrm{aB}}$ & $41,46^{\mathrm{aA}}$ & $28,93^{\mathrm{bC}}$ \\
\hline
\end{tabular}

Médias seguidas de mesma letra minúscula nas colunas e de mesma letra maiúscula nas linhas não diferem entre si segundo o teste de Tukey $(\mathrm{P}<0,05)$.

Os diferentes ambientes e tempos de armazenamento influenciam a qualidade fisiológica das sementes, sendo que, tempos superiores a oito meses de armazenamento e ambientes com temperaturas mais amenas proporcionaram melhores condições de germinação das mesmas. Novas pesquisas devem ser realizadas, objetivando conhecer o comportamento de sementes forrageiras oriundas de regiões com características edafoclimáticas distintas de regiões onde serão cultivadas, proporcionando dessa forma maiores condições de produção e produtividade das mesmas.

\section{REFERÊNCIAS}

AMATO,A.L.P.; MAIA, F.C.; MAIA, M.S.; CAETANO, L.S.; SIMIONI, S.B.; CONTO, L.; BONINI FILHO, R.M. Estabelecimento de condições de luz e temperatura para germinação de sementes de amendoim forrageiro.
Revista Brasileira de Sementes, v.29, n.3, p.61-66, 2007.

BRASIL. Ministério da Agricultura, do Abastecimento e da Reforma Agrária. Secretaria Nacional de Defesa Agropecuária. Regras para análises de sementes. Brasília, DF, 2009.

BRASIL. Ministério da Agricultura, Pecuária e Abastecimento. Registro Nacional de Cultivares. Brasília, 2011. Disponível em:

$<$ http://extranet.agricultura.gov.br/php/p roton/cultivarweb/cultivares_registradas .php>. Acesso em: 15 set. 2012.

CARVALHO, N.M.; NAKAGAWA, J. Sementes: ciência, tecnologia e produção. 4.ed. Jaboticabal: FUNEP, 2000. 588p.

COSTA,L.H.; ROSSETO, C.A.V. Rendimento e qualidade de sementes de amendoim forrageiro em diferentes épocas de colheita. Ciência Rural, v.38, n.8, p.2358-2361, 2008. 
COX, K.G. Seed production from

forage peanut. Queensland:

Department of Primary Industries and

Fisheries, 2012. Disponível em:

$<$ http://www2.dpi.qld.gov.au/pastures/1

5482.html> Acesso em: 8 set. 2012.

MAGUIRRE, J.D. Speed of

germination aid in selection and evaluation for seedling and vigour. Crop Science, v.2, n.2, p.176-177, 1962.

VALENTIM, J.F.; ANDRADE, C.M.S.; MENDONÇA, H.A.; SALES, M.F.L.

Velocidade de estabelecimento de acessos de amendoim forrageiro na Amazônia Ocidental. Revista

Brasileira de Zootecnia, v.32, n.6, p.1569-1577, 2003.

Data de recebimento: 05/07/2013

Data de aprovação: 17/09/2013 